Article

\title{
Preparation and Properties of Microarc Oxidation Self-Lubricating Composite Coatings on Aluminum Alloy
}

\author{
Zhenwei $\mathrm{Li}^{*}$ and Shichun Di \\ School of Mechatronics Engineering, Harbin Institute of Technology, Harbin 150001, China; dishichun@126.com \\ * Correspondence: 14b908070@hit.edu.cn
}

Academic Editor: Alexandru Mihai Grumezescu

Received: 22 January 2017; Accepted: 28 March 2017; Published: 5 April 2017

\begin{abstract}
Microarc oxidation (MAO) coatings were prepared on 2024-T4 aluminum alloy using pulsed bipolar power supply at different cathode current densities. The MAO ceramic coatings contained many crater-like micropores and a small number of microcracks. After the MAO coatings were formed, the coated samples were immersed into a water-based Polytetrafluoroethylene (PTFE) dispersion. The micropores and microcracks on the surface of the MAO coatings were filled with PTFE dispersion for preparing MAO self-lubricating composite coatings. The microstructure and properties of MAO coatings and the wear resistance of microarc oxidation self-lubricating composite coatings were analyzed by SEM, laser confocal microscope, X-ray diffractometry (XRD), Vickers hardness test, scratch test and ball-on-disc abrasive tests, respectively. The results revealed that the wear rates of the MAO coatings decreased significantly with an increase in cathode current density. Compared to the MAO coatings, the microarc oxidation self-lubricating composite coatings exhibited a lower friction coefficient and lower wear rates.
\end{abstract}

Keywords: 2024-T4 aluminum alloy; microarc oxidation; cathode current density; PTFE; adhesion strength; wear resistance

\section{Introduction}

Rich aluminum resources have already been discovered on the Earth. Aluminum alloy, due to its high specific strength, low density [1], proper corrosion resistance and great workability, has received much attention and is extensively applied in aerospace and transportation systems [2]. However, the application of aluminum alloy is seriously restricted by its low surface hardness, high and unstable friction coefficient, poor adhesive wear and severe abrasive wear [3-5]. To date, many aluminum alloy surface modification technologies, such as physical vapor deposition, ion beam assisted deposition, hard anodizing and thermal spraying, have been developed and employed to improve the hardness and wear resistance of aluminum alloy. However, most of these technologies require high temperatures and are complicated to employ. These technologies are also not environmentally friendly [6,7]. Microarc oxidation (MAO), namely plasma electrolytic oxidation (PEO) [8], emerged as a novel technique with broad application prospects $[9,10]$. MAO could be used to prepare ceramic-like oxide coatings on the surface of some light metals in-situ through anodic oxidation, thermochemistry, electrochemistry and plasma chemical mechanisms [11,12]. The ceramic coatings prepared by MAO have high hardness, good adhesion to substrate, and excellent wear resistance etc. [13-15].

The microstructure and properties of MAO coatings are influenced by many factors such as electrolyte composition, power supply modes, electrical parameters, processing time and additives. The pulsed bipolar current mode has received more attention and has been applied widely during MAO due to the prepared coatings having a more compact structure and superior performance. 
Hussein [16] investigated the effect of current mode (unipolar, bipolar) on the wear properties of MAO coatings on an AM60B magnesium alloy and found that the MAO coatings using a pulsed bipolar current mode exhibited better wear resistance. $\mathrm{Wu}$ [17] found that the composition, structure and physical and chemical properties of MAO coatings on the surface of Ti alloy can be extensively modified by changing the anodic and cathodic voltages. Liu [18] studied the effects of cathodic voltages on the structure and performance of MAO coatings prepared on NiTi alloy. Su [19] investigated the effects of cathode current density on corrosion resistance of MAO coatings on ZK60 Mg alloy. Li [20] discovered that the wear resistance of MAO coatings can be significantly improved by increasing the cathodic voltage. There is currently little work about cathode current density improving the structure and anti-wear of MAO coatings. Moreover, the MAO ceramic coatings produced also behave as a high friction coefficient, which limit the extensive engineering applications for MAO technology. MAO ceramic coatings contained many crater-like micropores of various sizes and a small number of microcracks. This creates the possibility to deposit small sized lubricants into these micropores and microcracks to form microarc oxidation self-lubricating composite coatings.

The microarc oxidation self-lubricating composite coatings could possess relatively improved hardness and higher anti-wear attributes as well as self-lubricating performance coupled with a lower friction coefficient. MAO self-lubricating composite coatings are extensively applied in extreme working conditions where liquid lubricants and greases are too volatile to function, such as high vacuum, chemical, high temperature and radioactive environments. Moreover, MAO self-lubricating composite coatings are also useful in industrial applications to avoid contamination through use of lubricating oil or grease.

PTFE has low shear strength and is often used as a solid lubricant. Moreover, PTFE dispersion has good liquidity. In this study, a 2024-T4 aluminum alloy was treated through microarc oxidation using a pulsed bipolar current mode at different cathode current densities. After the MAO coatings were formed, the micropores and microcracks on the surface of the MAO ceramic coatings were filled with PTFE dispersion for preparing MAO self-lubricating composite coatings containing PTFE. The microstructure and properties of MAO coatings, and the wear resistance of the microarc oxidation self-lubricating composite coatings were investigated. The adhesion strength between the MAO coatings and substrates are also analyzed.

\section{Experimental Details}

\subsection{Samples Preparation}

The MAO coatings were prepared on a 2024-T4 aluminum alloy. The main chemical composition (mass fraction, wt. \%) of the 2024-T4 aluminum alloy is $3.8-4.9 \% \mathrm{Cu}, 0.5 \% \mathrm{Si}, 0.5 \% \mathrm{Fe}, 0.3-0.9 \% \mathrm{Mn}$, $1.2-1.8 \% \mathrm{Mg}, 0.25 \% \mathrm{Zn}, 0.10 \% \mathrm{Cr}, 0.15 \% \mathrm{Ti}$, balanced with Al. The main mechanical properties of the 2024-T4 aluminum alloy are a yield stress $\left(0.2 \%\right.$ offset) of $\sigma_{0.2}=325 \mathrm{MPa}$, a tensile strength of $\sigma_{\mathrm{b}}=470 \mathrm{MPa}$, a Vickers hardness of $130 \mathrm{Hv}$, an elongation of $\delta=20 \%$ and a Young modulus of $69 \mathrm{GPa}$, respectively. The sample size was $30 \mathrm{~mm} \times 15 \mathrm{~mm} \times 2 \mathrm{~mm}$. Samples were polished using abrasive papers from $600 \#$ to $2000 \#$, degreased by ultrasound in acetone, rinsed in deionized water, and then dried in warm air. The AC pulse microarc oxidation unit was used in this experiment. The sample was used as the anode and the electrolytic tank was used as the cathode. The silicate electrolyte was prepared in deionized water. The composition of electrolyte contained $(6 \mathrm{~g} / \mathrm{L}) \mathrm{Na}_{2} \mathrm{SiO}_{3},(1.5 \mathrm{~g} / \mathrm{L}) \mathrm{KOH}$, and was of high purity. A pulsed bipolar constant current power supply was used in this experiment. The schematic of pulse output of bipolar constant current power supply is shown in Figure 1 and the MAO process parameters are listed in Table 1. The mixing pump was opened and the electrolyte was stirred continuously during MAO treatment. The cycle cooling system was opened to ensure that the electrolyte temperature was less than $40^{\circ} \mathrm{C}$. After the microarc oxidation coatings were formed, the coated samples were rinsed with deionized water and dried in warm air. 


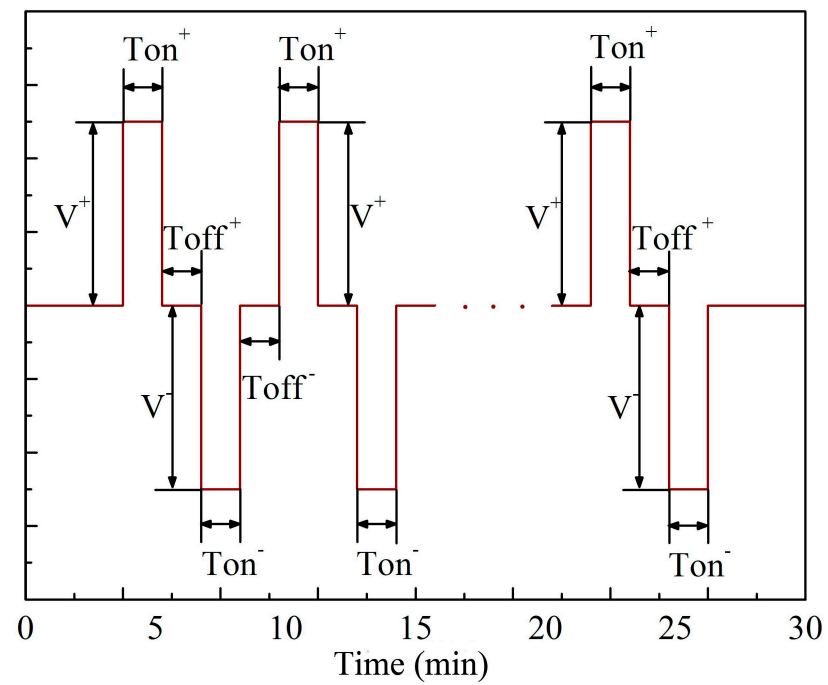

Figure 1. Schematic of pulse output of bipolar constant current power supply.
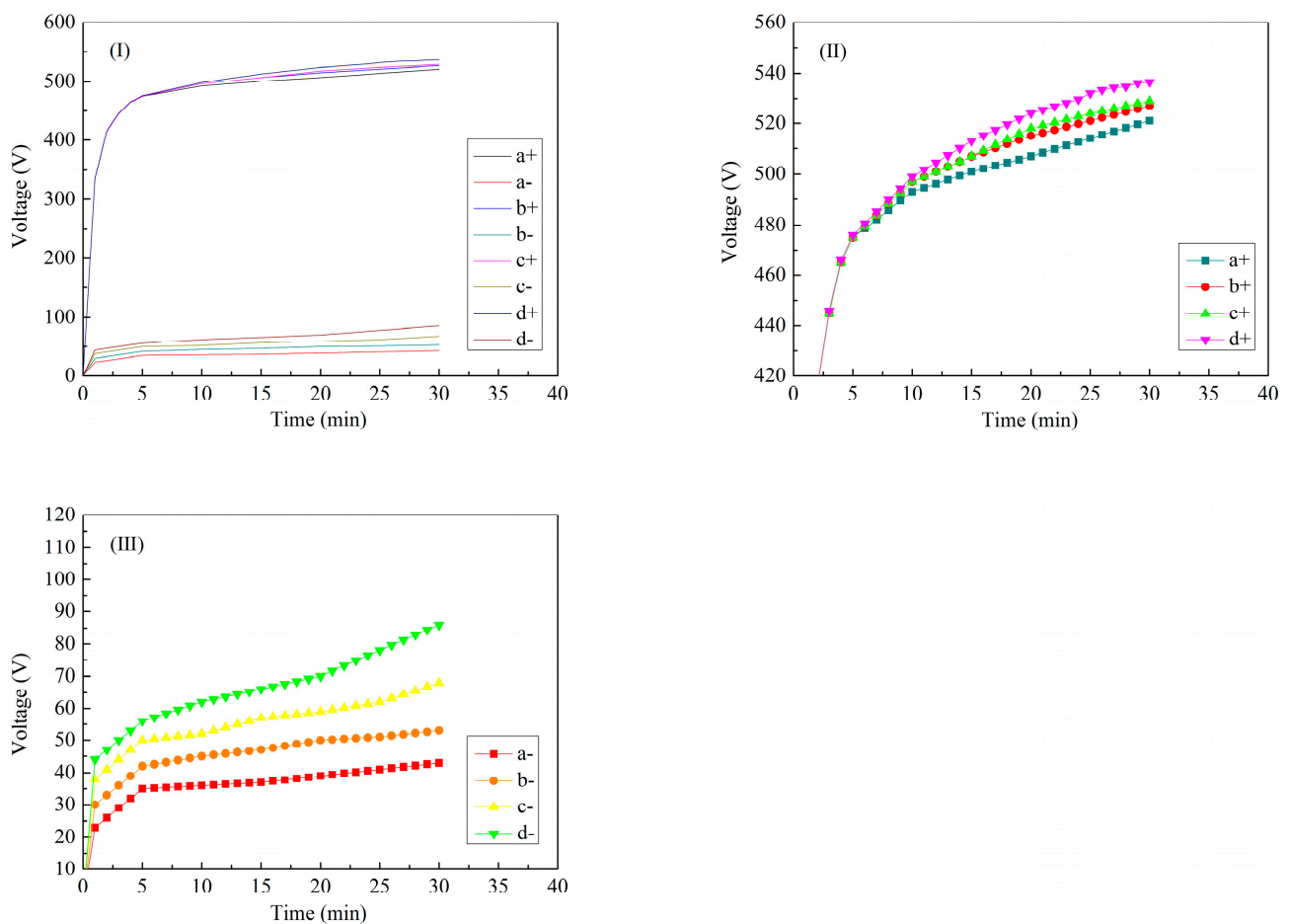

Figure 2. Variation curves of voltage at different cathode current densities during microarc oxidation. (I) variation curves of anode and cathode voltages; (II) variation curves of anode voltages; (III) variation curves of cathode voltages; (a) $9 \mathrm{~A} / \mathrm{dm}^{2}$; (b) $18 \mathrm{~A} / \mathrm{dm}^{2}$; (c) $27 \mathrm{~A} / \mathrm{dm}^{2}$; (d) $37 \mathrm{~A} / \mathrm{dm}^{2}$.

Table 1. Microarc oxidation process parameters for coatings formed on aluminum alloy at different cathode current densities.

\begin{tabular}{|c|c|c|c|c|c|c|c|c|c|}
\hline Labels & $\begin{array}{l}\text { Ton }{ }^{+} \\
(\mu s)\end{array}$ & $\begin{array}{c}\text { Toff }^{+} \\
(\mu s)\end{array}$ & $\begin{array}{c}\text { Ton }^{-} \\
(\mu s)\end{array}$ & $\begin{array}{c}\text { Toff }^{-} \\
(\mu s)\end{array}$ & $\mathrm{V}^{+}(\mathrm{V})$ & $\mathrm{V}^{-}(\mathrm{V})$ & $\begin{array}{c}\mathrm{I}^{+} \\
\left(\mathrm{A} / \mathrm{dm}^{2}\right)\end{array}$ & $\begin{array}{c}\mathrm{I}^{-} \\
\left(\mathrm{A} / \mathrm{dm}^{2}\right)\end{array}$ & $\begin{array}{l}\text { Time } \\
\text { (min) }\end{array}$ \\
\hline a (a1) & 2000 & 800 & 2000 & 800 & Figure 2 & Figure 2 & 46 & 9 & 30 \\
\hline b (b1) & 2000 & 800 & 2000 & 800 & Figure 2 & Figure 2 & 46 & 18 & 30 \\
\hline $\mathrm{c}(\mathrm{c} 1)$ & 2000 & 800 & 2000 & 800 & Figure 2 & Figure 2 & 46 & 27 & 30 \\
\hline $\mathrm{d}(\mathrm{d} 1)$ & 2000 & 800 & 2000 & 800 & Figure 2 & Figure 2 & 46 & 37 & 30 \\
\hline
\end{tabular}


The coated samples were immersed into water-based PTFE dispersion. The deposition time was $15 \mathrm{~min}$. The micropores and microcracks on the surface of the MAO coatings were filled with the PTFE dispersion. The samples were heated for $40 \mathrm{~min}$ at $220^{\circ} \mathrm{C}$ and the PTFE dispersion solidified. The PTFE was embedded into the micropores and microcracks of the MAO ceramic coatings, which formed microarc oxidation self-lubricating composite coatings containing PTFE. The parameters for preparing the microarc oxidation self-lubricating composite coatings are listed in Table 1.

\subsection{Testing and Characterization}

The morphologies of microarc oxidation ceramic coatings formed using pulsed bipolar power supply at different cathode current densities and the morphologies of the microarc oxidation self-lubricating composite coatings were observed by FEI Sirion scanning electron microscopy (SEM). The surface roughness of microarc oxidation ceramic coatings was measured by a OLS3000 laser confocal microscope. The phase structure of the microarc oxidation ceramic coatings was analyzed by $X^{\prime}$ Pert PRO X-ray spectroscopy (XRD).

Adhesion strength of microarc oxidation coatings was evaluated using a CSM microscratch tester. In this test, the load on a diamond Rockwell indenter with a tip radius of $100 \mu \mathrm{m}$ was linearly increased from 0 to $30 \mathrm{~N}$ at a normal loading speed of $30 \mathrm{~N} \mathrm{~min}^{-1}$ as the diamond is drawn across the surface of the MAO coatings. The scratch length was $5 \mathrm{~mm}$. The critical load values $\left(L_{\mathrm{c}}\right)$ were determined using supplementary data graphics including acoustic emission and friction coefficient.

Hardness was measured by Vickers hardness tester and the load was $10 \mathrm{~N}$ and the dwelling time was $10 \mathrm{~s}$. For each sample, tests carried out six times. The friction coefficient of the MAO coatings and the microarc oxidation self-lubricating composite coatings was measured by CETR-UMT-2 ball-on-disk wear tester. WC balls with a diameter of $5 \mathrm{~mm}$ and a surface roughness greater than $0.05 \mu \mathrm{m}$ were used as counterface materials. All wear tests were conducted with WC balls in sliding contact with a load of $10 \mathrm{~N}$ at a fixed sliding speed. The rotating diameter and rotating speed of the wear tester were $6 \mathrm{~mm}$ and $200 \mathrm{RPM}$, respectively. The test time of each sample measured on the wear tester was $20 \mathrm{~min}$. The width of the wear tracks were measured via SEM and OLS3000 laser confocal microscope. The depth and volume of the wear tracks were detected by OLS3000 laser confocal microscope. The average value of the three profiles on the wear tracks was used to calculate the wear rate. The computation formula of wear rate is as Equation (1) [21]. In Equation (1) $Q$ is the wear rate, $V_{W}$ is the wear volume $\left(\mathrm{mm}^{3}\right), P$ is the applied load $(\mathrm{N})$, and $S$ is the sliding distance $(\mathrm{m})$.

$$
\mathrm{Q}=\frac{V_{\mathrm{W}}}{P S}
$$

\section{Results and Discussion}

\subsection{Microstructure of MAO Coatings and MAO Self-Lubricating Composite Coatings}

The variation curves of voltages are shown in Figure 2. In Figure 2I the anode and cathode voltages increased as the MAO processing time increased during microarc oxidation. The resistance of MAO coatings increased as MAO coatings grew, resulting in an increase of anode and cathode voltages under the constant current mode during MAO. Moreover, Figure 2II,III shows that the growth rates of anode and cathode voltages increased in association with cathode current density, which may be related to the growth rate of MAO coatings during MAO.

The surface morphologies of microarc oxidation ceramic coatings prepared on the surface of 2024-T4 aluminum alloy using pulsed bipolar power supply at different cathode current densities are shown in Figure 3. MAO ceramic coatings contained many crater-like micropores of various sizes and a small number of microcracks. The quantity of micropores on the surface of MAO ceramic coatings decreased significantly as the cathode current density increased from nine to $37 \mathrm{~A} / \mathrm{dm}^{2}$. These micropores were formed by molten "oxide magma" and the gas bubbles ejected from discharge 
channels. The rapid solidification of molten oxide magma ejected from discharge channels in the electrolyte, however, also produced thermal stress, which caused microcracks [22].

As shown in Figure 3, A-type holes, B-type holes, and C-type holes were clearly exhibited on the surface of MAO coatings. A-type holes and C-type holes showed a porous foam-like structure. B-type holes looked like flat pancakes and showed a more compact structure. According to previous studies, three typical discharge events occurred in the process of MAO. A-type discharge events occurred in holes on the surface of MAO coatings. B-type discharge events penetrated through MAO coatings. C-type discharge events occurred in the relatively deep holes on the surface of MAO coatings. A-type holes, B-type holes and C-type holes were formed by A-type discharge events, B-type discharge events and C-type discharge events, respectively [23]. Li [20] hypothesized that B-type discharge events may result in the formation of new oxides, and the existence of the cathode current can promote the occurrence of B-type discharge events. At the same time, the existence of the cathode current decreased the occurrence of A-type discharge events and C-type discharge events. Therefore, it can be inferred that with the increase in cathode current density, B-type discharge events increase and MAO coatings become more compact.

The surface roughness of microarc oxidation ceramic coatings is shown in Figure 4 . The surface roughness of the microarc oxidation coatings increased significantly with the increase in cathode current density. As shown in Figure 3, the foam-like structures were more porous and higher than the pancake-like structures. The foam-like structures decreased in size with the increase in cathode current density, which can decrease the surface roughness of microarc oxidation coatings. The pancake-like structures increased in size and quantity with an increase in the cathode current density. This is due to the increase of the B-type discharge intensity, the quantity of the formed molten oxide magma on the coatings/substrates interface, the pressure in the discharge channels, and the ejected height of the molten oxide magma.
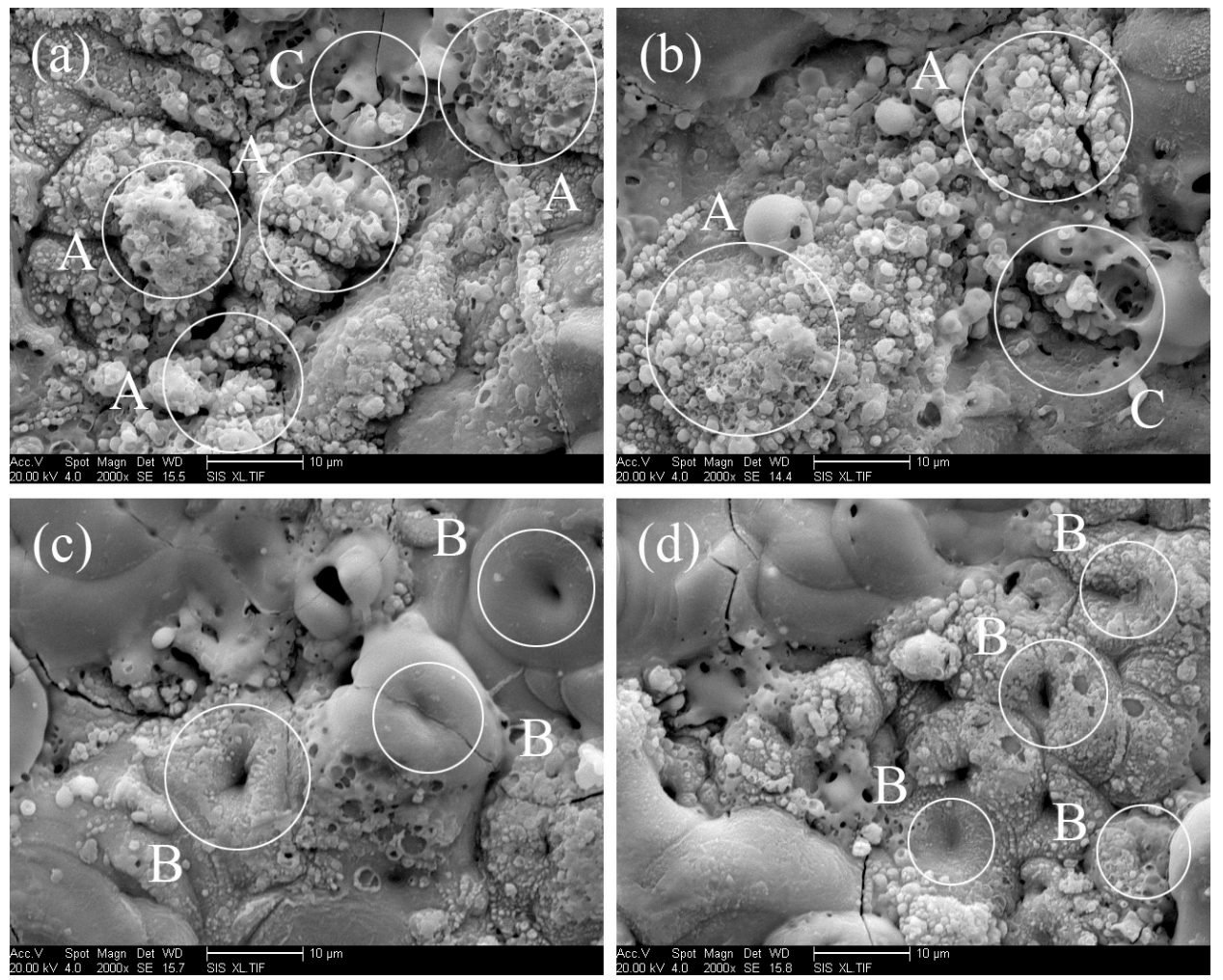

Figure 3. Surface morphologies of microarc oxidation coatings formed on aluminum alloy at different cathode current densities. (a) $9 \mathrm{~A} / \mathrm{dm}^{2}$; (b) $18 \mathrm{~A} / \mathrm{dm}^{2}$; (c) $27 \mathrm{~A} / \mathrm{dm}^{2}$; (d) $37 \mathrm{~A} / \mathrm{dm}^{2}$. 


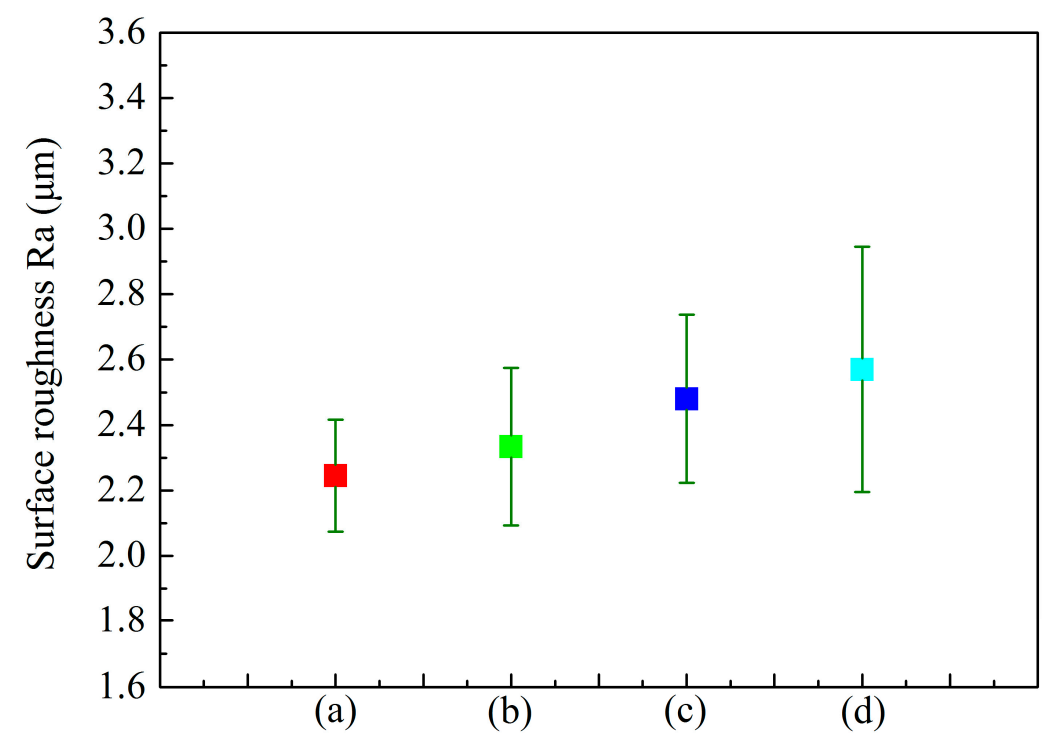

Figure 4. The surface roughness of microarc oxidation coatings formed on aluminum alloy at different cathode current densities. (a) $9 \mathrm{~A} / \mathrm{dm}^{2}$; (b) $18 \mathrm{~A} / \mathrm{dm}^{2}$; (c) $27 \mathrm{~A} / \mathrm{dm}^{2}$; (d) $37 \mathrm{~A} / \mathrm{dm}^{2}$.

The cross-sectional morphologies of microarc oxidation ceramic coatings are shown in Figure 5. Figure 5I shows the defects and micropores. In MAO coatings, the defects and micropores decreased significantly with an increase in cathode current density, and the MAO coatings became more compact. As shown in Figure 3, B-type holes looked like flat pancakes and showed a more compact structure. B-type holes formed by B-type discharge events increased and the MAO coatings became more compact with the increase in cathode current density. Moreover, B-type discharge events penetrated through the entire MAO coating resulting in the formation of a new oxide. B-type discharge events and the quantity of the formed molten oxide magma on the coatings/substrates interface increased with the increase in cathode current density. The molten oxide magma was ejected from discharge channels and the defects and micropores in the MAO coatings were filled with the molten oxide magma. The molten oxide magma rapidly solidified and formed increasingly more compact MAO coatings.

The thickness of microarc oxidation ceramic coatings is shown in Figure 6. The thickness of MAO ceramic coatings increased with an increase in cathode current density. As shown in Figure 3, the foam-like structures decreased in size and quantity with the increase in cathode current density, which decreased the growth rates of MAO coatings. The B-type discharge events, B-type discharge intensity, the non-uniformity of B-type discharge events on the surface of the MAO coatings, the quantity of the molten oxide magma formed on the coatings/substrates interface, the pressure in the discharge channels and the ejected height of the molten oxide magma increased along with the cathode current density. This increased the growth rates and the non-uniformity of the thickness of the MAO coatings.

The surface morphologies of microarc oxidation self-lubricating composite coatings are shown in Figure 7. The micropores and microcracks on the surface of MAO ceramic coatings were filled with the PTFE dispersion.

\subsection{Effect of Cathode Current Density on Phase Structure of MAO Ceramic Coatings}

The phase structure of microarc oxidation ceramic coatings is shown in Figure 8. XRD analysis results revealed that the $\mathrm{MAO}$ ceramic coatings were made up of $\gamma-\mathrm{Al}_{2} \mathrm{O}_{3}$, and a small amount of $\alpha-\mathrm{Al}_{2} \mathrm{O}_{3}$ and mullite. The intensity of three typical $\gamma-\mathrm{Al}_{2} \mathrm{O}_{3}$ peaks is listed in Table 2 . The intensity of $\gamma-\mathrm{Al}_{2} \mathrm{O}_{3}$ peaks increased with the increase in the cathode current density. B-type discharge events penetrated through the entire MAO coating and can promote the formation of the new molten oxide magma on the interface of coatings/substrates. Moreover, the B-type discharge events, the B-type 
discharge intensity, the quantity of the formed molten oxide magma on the coatings/substrates interface, the pressure in the discharge channels and the ejected height of the molten oxide magma increased along with the cathode current density. This increased the growth rates, the thickness and the compactness of the MAO coatings.
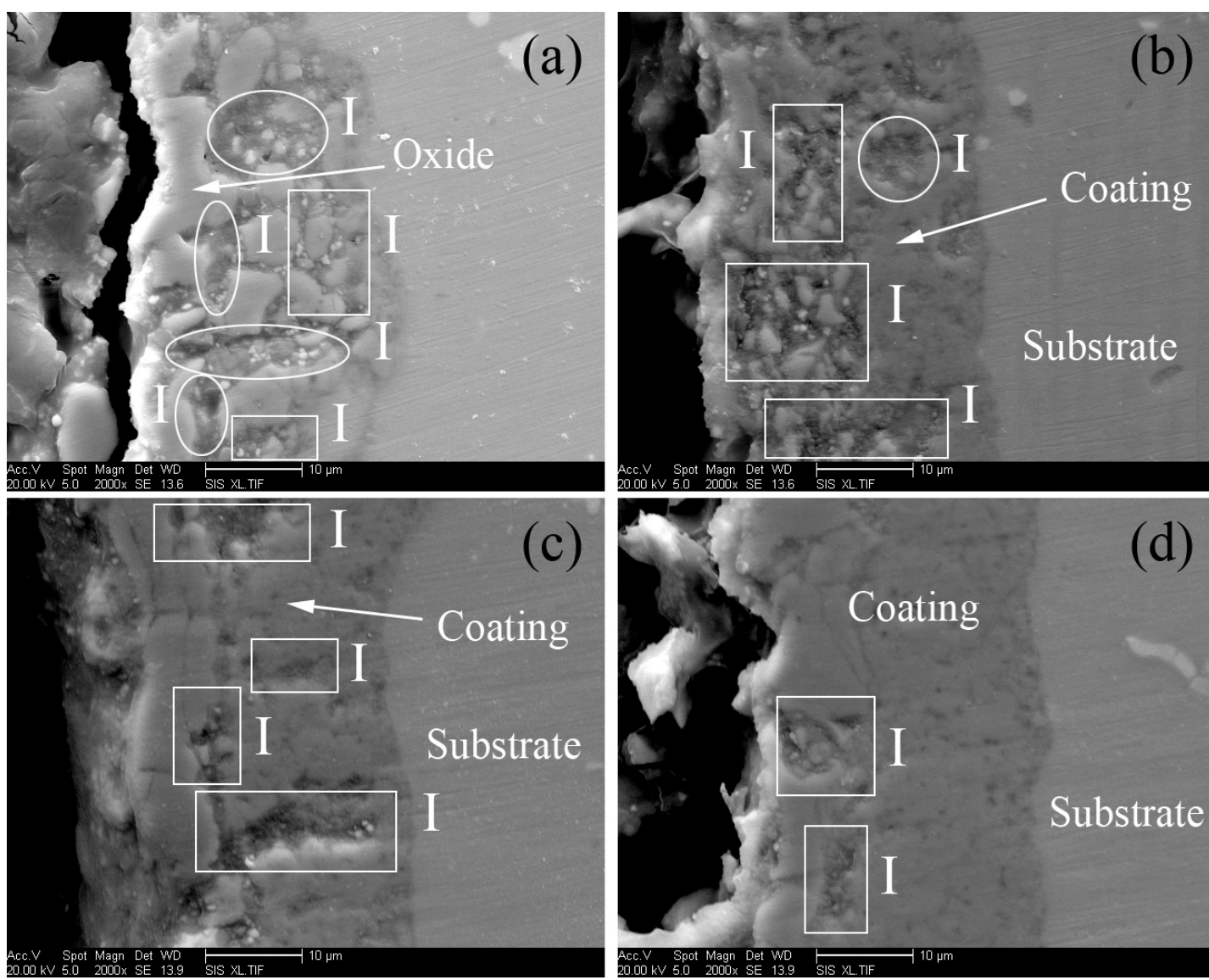

Figure 5. The cross-section morphologies of microarc oxidation coatings formed on aluminum alloy at different cathode current densities. (a) $9 \mathrm{~A} / \mathrm{dm}^{2}$; (b) $18 \mathrm{~A} / \mathrm{dm}^{2}$; (c) $27 \mathrm{~A} / \mathrm{dm}^{2}$; (d) $37 \mathrm{~A} / \mathrm{dm}^{2}$.

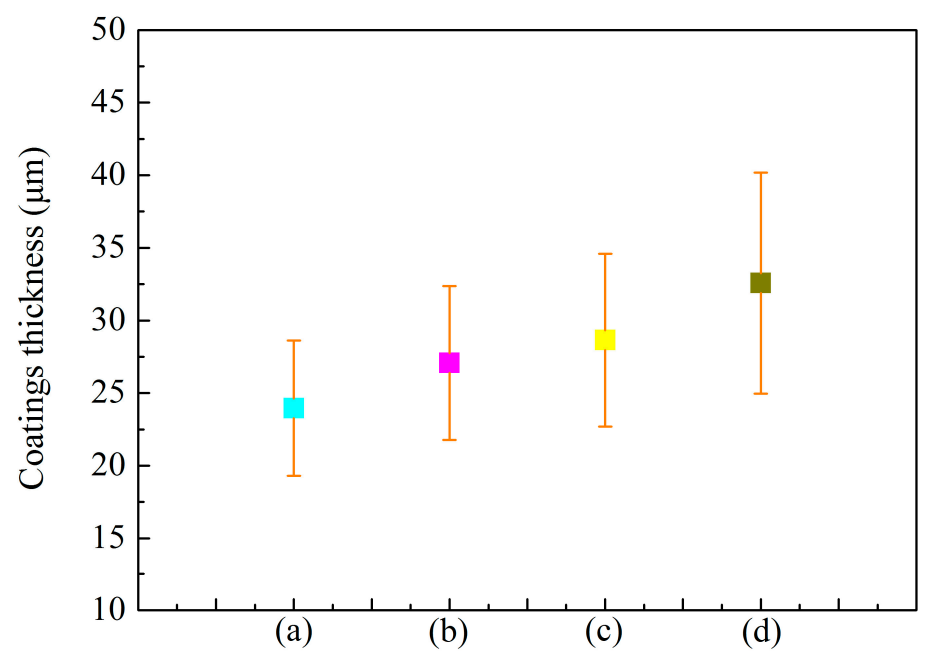

Figure 6. The thickness of microarc oxidation coatings formed on aluminum alloy at different cathode current densities. (a) $9 \mathrm{~A} / \mathrm{dm}^{2}$; (b) $18 \mathrm{~A} / \mathrm{dm}^{2}$; (c) $27 \mathrm{~A} / \mathrm{dm}^{2}$; (d) $37 \mathrm{~A} / \mathrm{dm}^{2}$. 

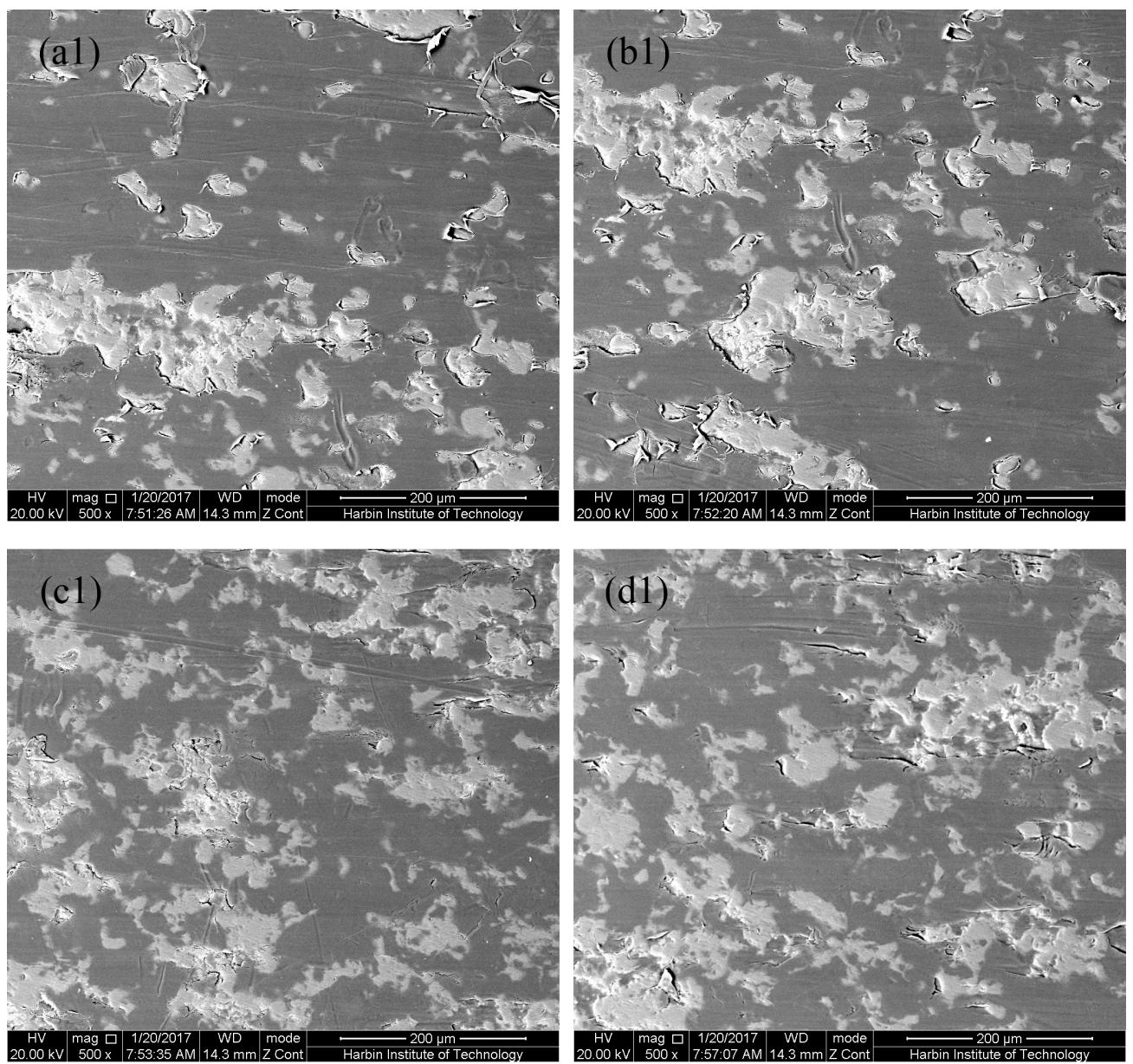

Figure 7. The surface morphologies of microarc oxidation self-lubricating composite coatings formed on aluminum alloy at different cathode current densities. (a1) $9 \mathrm{~A} / \mathrm{dm}^{2}$; (b1) $18 \mathrm{~A} / \mathrm{dm}^{2}$; (c1) $27 \mathrm{~A} / \mathrm{dm}^{2}$; (d1) $37 \mathrm{~A} / \mathrm{dm}^{2}$.
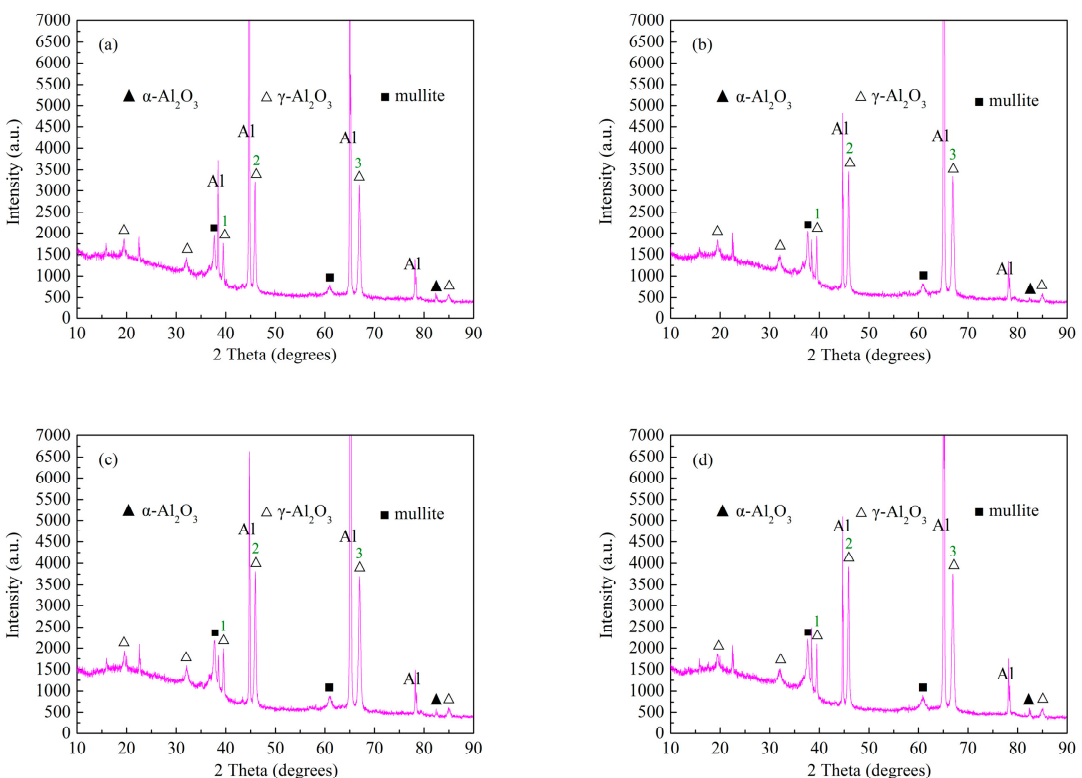

Figure 8. X-ray diffractometry (XRD) pattern of microarc oxidation coatings formed on aluminum alloy at different cathode current densities. (a) $9 \mathrm{~A} / \mathrm{dm}^{2}$; (b) $18 \mathrm{~A} / \mathrm{dm}^{2}$; (c) $27 \mathrm{~A} / \mathrm{dm}^{2}$; (d) $37 \mathrm{~A} / \mathrm{dm}^{2}$. 
Table 2. The intensity of $\gamma-\mathrm{Al}_{2} \mathrm{O}_{3}$ peaks in microarc oxidation (MAO) coatings formed on aluminum alloy at different cathode current densities.

\begin{tabular}{ccccc}
\hline \multirow{2}{*}{ Labels } & \multicolumn{4}{c}{ Intensity (a.u.) } \\
\cline { 2 - 5 } & $\mathbf{a}$ & $\mathbf{b}$ & $\mathbf{c}$ & $\mathbf{d}$ \\
\hline 1 & 1765 & 1917 & 1992 & 2101 \\
2 & 3206 & 3458 & 3809 & 3921 \\
3 & 3143 & 3345 & 3698 & 3759 \\
\hline
\end{tabular}

\subsection{Effect of Cathode Current Density on Adhesion Strength of MAO Ceramic Coatings}

Figures 9 and 10 shows the SEM morphologies and supplementary data graphics of scratches on microarc oxidation coatings, respectively. The critical loads at which the acoustic emission and friction coefficient increased sharply are indicated on the graphs. The corresponding critical load values are summarized in Table 3. An increase in cathode current density creates corresponding critical load values in the microarc oxidation coatings. Tekin [24] suggests that the bonding strength between coatings and substrates, and the cohesion of inter-particles can be improved by decreasing micropores size and porosity on the surface of microarc oxidation coatings. The compactness of microarc oxidation coatings, the bonding strength between coatings and substrates, as well as the cohesion of inter-particles increased with the increase in cathode current density.

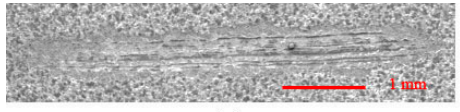

(a)

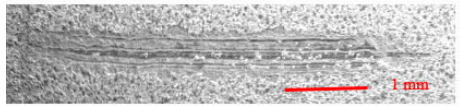

(c)

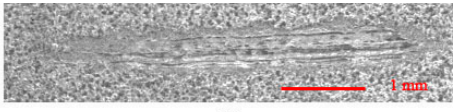

(b)

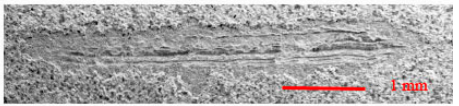

(d)

Figure 9. The SEM morphologies of scratches on the microarc oxidation coatings formed on aluminum alloy at different cathode current densities. (a) $9 \mathrm{~A} / \mathrm{dm}^{2}$; (b) $18 \mathrm{~A} / \mathrm{dm}^{2}$; (c) $27 \mathrm{~A} / \mathrm{dm}^{2}$; (d) $37 \mathrm{~A} / \mathrm{dm}^{2}$.
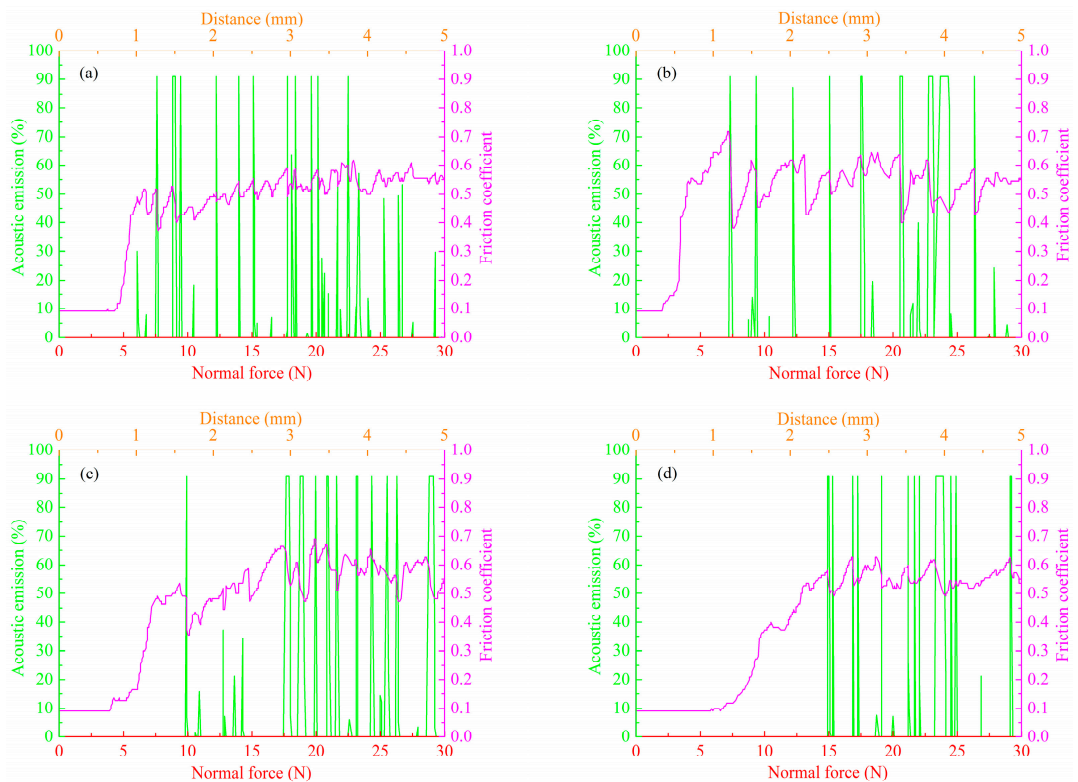

Figure 10. The supplementary data graphics of scratches on the microarc oxidation coatings formed on aluminum alloy at different cathode current densities. (a) $9 \mathrm{~A} / \mathrm{dm}^{2}$; (b) $18 \mathrm{~A} / \mathrm{dm}^{2}$; (c) $27 \mathrm{~A} / \mathrm{dm}^{2}$; (d) $37 \mathrm{~A} / \mathrm{dm}^{2}$. 
Table 3. Critical load values of MAO coatings formed on aluminum alloy at different cathode current densities.

\begin{tabular}{cc}
\hline Coatings & Lc (N) \\
\hline A (Figure 6a) & 6.17 \\
B (Figure 6b) & 7.33 \\
C (Figure 6c) & 9.83 \\
D (Figure 6d) & 15.00 \\
\hline
\end{tabular}

\subsection{Effect of Cathode Current Density on Wear Resistance of MAO Ceramic Coatings}

The hardness of microarc oxidation ceramic coatings is shown in Figure 11. With the increase in cathode current density, the hardness of MAO ceramic coatings increased significantly. B-type discharge events increased with the increase in cathode current density, which improved the compactness and the hardness of microarc oxidation coatings.

Figure 12 shows the friction coefficient of microarc oxidation coatings against WC balls at room temperature during wear testing. It was discovered that wave peaks existed on the surface of MAO ceramic coatings, and the friction coefficient rose rapidly in the initial stages of the friction test. After $500 \mathrm{~s}$, the wave peaks were smoothed flat and the friction coefficient stabilized. The friction coefficient of MAO ceramic coatings ranged $0.65-0.8$, determined by the performance of the ceramic itself. Moreover, the friction coefficient was significantly affected by the cracks and pores on the MAO coatings. The wave peaks on the surface of the WC balls were easy to penetrate into the surface of the MAO coatings due to the high porosity of the MAO coatings. This increased the contact area between WC balls and MAO coatings as well as the friction coefficient. The uneven distribution of the cracks and pores on the surface of the MAO coatings increased the fluctuation range of the friction coefficient. Easy of penetration by wave peaks on the surface of the WC balls created serious abrasive wear and produced a significant quantity of wear debris during wear testing. The microcracks on the MAO coatings were easy to expand and form exfoliation under periodically applied load during wear testing. The wear debris and exfoliation were involved in the friction process, which significantly affected the friction coefficient.

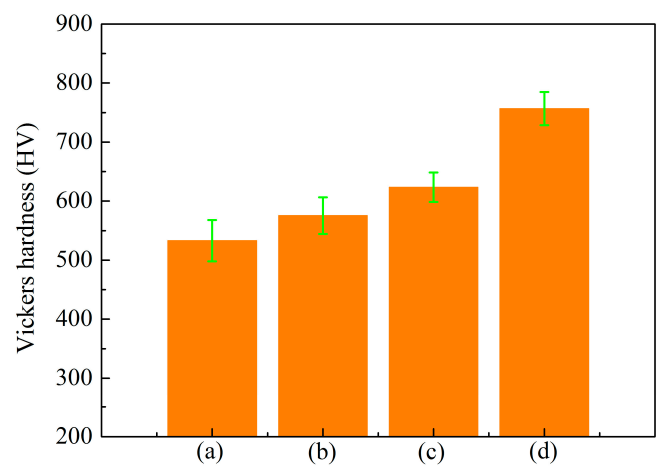

Figure 11. The hardness of microarc oxidation coatings formed on aluminum alloy at different cathode current densities. (a) $9 \mathrm{~A} / \mathrm{dm}^{2}$; (b) $18 \mathrm{~A} / \mathrm{dm}^{2}$; (c) $27 \mathrm{~A} / \mathrm{dm}^{2}$; (d) $37 \mathrm{~A} / \mathrm{dm}^{2}$.

Figure 13 shows the morphologies of wear tracks for microarc oxidation coatings against WC balls at room temperature after wear testing. The morphologies of wear tracks for MAO coatings exhibited furrows and a wide range of exfoliation. This revealed that the dominant wear mechanism of microarc oxidation ceramic coatings was abrasive and fatigue wear. Moreover, the furrows and the region of exfoliation reduced in size with the increase in cathode current density. The hardness of porous MAO coatings was low and the microbulges on the surface of the WC balls were easy to penetrate into the surface of MAO coatings and formed furrows during wear testing. As shown in Figure 5I, the defects 
and micropores in MAO coatings formed crack sources that expanded and created exfoliation under periodically applied load during wear testing. The compactness and hardness of the MAO coatings increased, the porosity and defects in the MAO coatings decreased, and the furrows and region of exfoliation decreased in size with the increase in cathode current density.

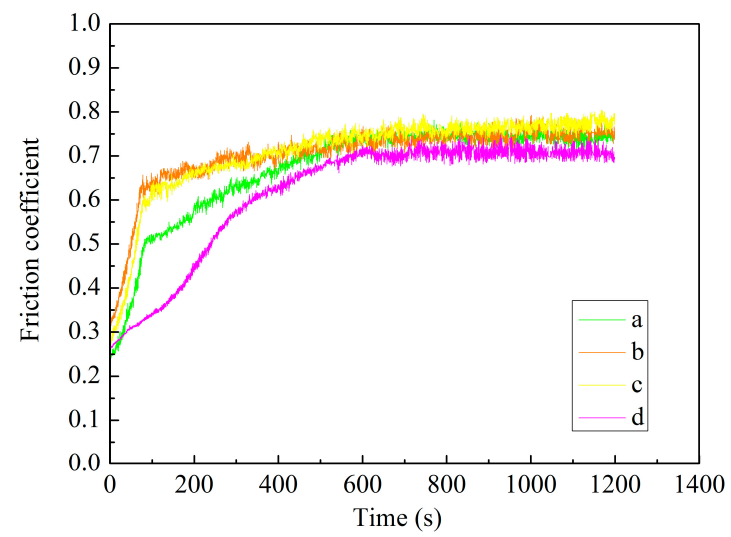

Figure 12. Friction coefficient of microarc oxidation coatings formed on aluminum alloy at different cathode current densities. (a) $9 \mathrm{~A} / \mathrm{dm}^{2}$; (b) $18 \mathrm{~A} / \mathrm{dm}^{2}$; (c) $27 \mathrm{~A} / \mathrm{dm}^{2}$; (d) $37 \mathrm{~A} / \mathrm{dm}^{2}$.
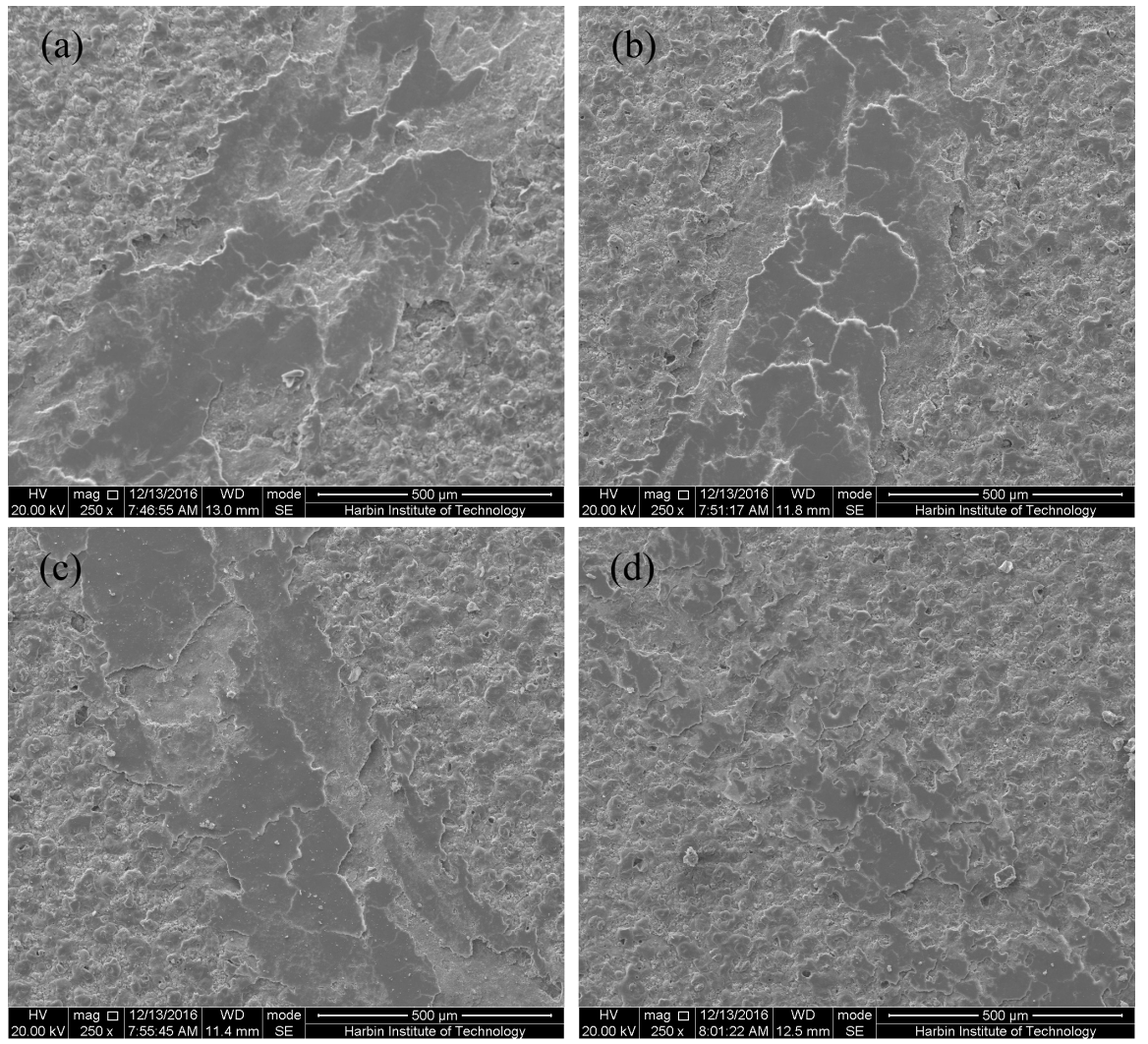

Figure 13. The morphologies of wear tracks for microarc oxidation coatings formed on aluminum alloy at different cathode current densities. (a) $9 \mathrm{~A} / \mathrm{dm}^{2}$; (b) $18 \mathrm{~A} / \mathrm{dm}^{2}$; (c) $27 \mathrm{~A} / \mathrm{dm}^{2}$; (d) $37 \mathrm{~A} / \mathrm{dm}^{2}$.

Table 4 shows the wear rates of MAO coatings. The wear rates of MAO coatings reduced significantly with the increase in cathode current density. As shown in Figures 3 and 5, the porosity and defects of the MAO coatings decreased with the increase in cathode current density, which significantly decreased the furrows, exfoliation and the wear rates of the MAO coatings during wear testing. 
Table 4. Wear rates of MAO coatings formed on aluminum alloy at different cathode current densities.

\begin{tabular}{ccccc}
\hline Coatings & $\begin{array}{c}\text { Wear Time } \\
(\mathbf{s})\end{array}$ & $\begin{array}{c}\text { Wear Track Width } \\
(\boldsymbol{\mu \mathbf { m } )}\end{array}$ & $\begin{array}{c}\text { Wear Track Depth } \\
(\boldsymbol{\mu \mathbf { m } )}\end{array}$ & $\begin{array}{c}\text { Wear Rate } \\
\left(\mathbf{m m}^{\mathbf{3}} \cdot \mathbf{N}^{-\mathbf{1}} \cdot \mathbf{m}^{-\mathbf{1}}\right)\end{array}$ \\
\hline $\mathrm{a}$ & 1200 & 630.84 & 4.79 & $0.20 \times 10^{-5}$ \\
$\mathrm{~b}$ & 1200 & 584.11 & 4.43 & $0.18 \times 10^{-5}$ \\
$\mathrm{c}$ & 1200 & 537.38 & 4.08 & $0.17 \times 10^{-5}$ \\
$\mathrm{~d}$ & 1200 & 443.93 & 3.37 & $0.14 \times 10^{-5}$ \\
\hline
\end{tabular}

\subsection{Proposed Wear Mechanism of MAO Ceramic Coatings}

Based on the friction behavior of microarc oxidation coatings, the wear mechanism of microarc oxidation coatings was as follows.

As shown in Figure 3, the hardness of porous MAO coatings formed by A-type discharge events and C-type discharge events was low due to high porosity of MAO coatings. The microbulges on the surface of the WC balls were easy to penetrate into the surface of MAO coatings, which formed serious abrasive wear during wear testing. B-type discharge events increased with the increase in cathode current density, improving the compactness and hardness of MAO coatings. This could make the microbulges on the surface of the WC balls penetrate into the surface of MAO coatings more difficult, and reduced the abrasive wear during wear testing.

As shown in Figure 3, some microcracks existed on the surface of MAO coatings and these microcracks were easy to expand and form exfoliation under periodically applied load during wear testing.

As shown in Figure 5I, many micropores and other defects on MAO coatings contributed to the formation of crack sources. These crack sources expand and create exfoliation under periodically applied load during wear testing. B-type discharge events increased with the increase in cathode current density, which decreased the porosity and defects in MAO coatings and improved the compactness of MAO coatings. This decreased the formation of crack sources and exfoliation during wear testing.

\subsection{Tribological Properties of MAO Self-Lubricating Composite Coatings}

Figure 14 shows the friction coefficient of MAO self-lubricating composite coatings against WC balls at room temperature during wear testing. Compared to MAO coatings, MAO self-lubricating composite coatings exhibited a lower friction coefficient of 0.09-0.15.

Figure 15 shows the morphologies of wear tracks for MAO self-lubricating composite coatings against WC balls at room temperature after wear testing. The morphologies of wear tracks for MAO coatings did not exhibit a significant quantity of furrows or exfoliation. It can be inferred that the dominant wear mechanism of microarc oxidation ceramic coatings was mild abrasive wear.

Table 5 shows the wear rates of MAO self-lubricating composite coatings. As shown in Figure 16, a comparison between the wear rates of MAO coatings and the wear rates of MAO self-lubricating composite coatings found that MAO self-lubricating composite coatings exhibited lower wear rates.

Table 5. Wear rates of MAO self-lubricating composite coatings formed on aluminum alloy at different cathode current densities.

\begin{tabular}{ccccc}
\hline Coatings & $\begin{array}{c}\text { Wear } \\
\text { Time/s }\end{array}$ & $\begin{array}{c}\text { Wear Track } \\
\text { Width }(\boldsymbol{\mu m})\end{array}$ & $\begin{array}{c}\text { Wear Track } \\
\text { Depth }(\boldsymbol{\mu m})\end{array}$ & $\begin{array}{c}\text { Wear Rate } \\
\left(\mathbf{m m}^{\mathbf{3}} \cdot \mathbf{N}^{-\mathbf{1}} \cdot \mathbf{m}^{-\mathbf{1}}\right)\end{array}$ \\
\hline a1 & 1200 & 518.69 & 3.94 & $0.16 \times 10^{-5}$ \\
b1 & 1200 & 364.48 & 2.77 & $0.11 \times 10^{-5}$ \\
c1 & 1200 & 303.74 & 2.31 & $0.96 \times 10^{-6}$ \\
d1 & 1200 & 238.32 & 1.81 & $0.75 \times 10^{-6}$ \\
\hline
\end{tabular}




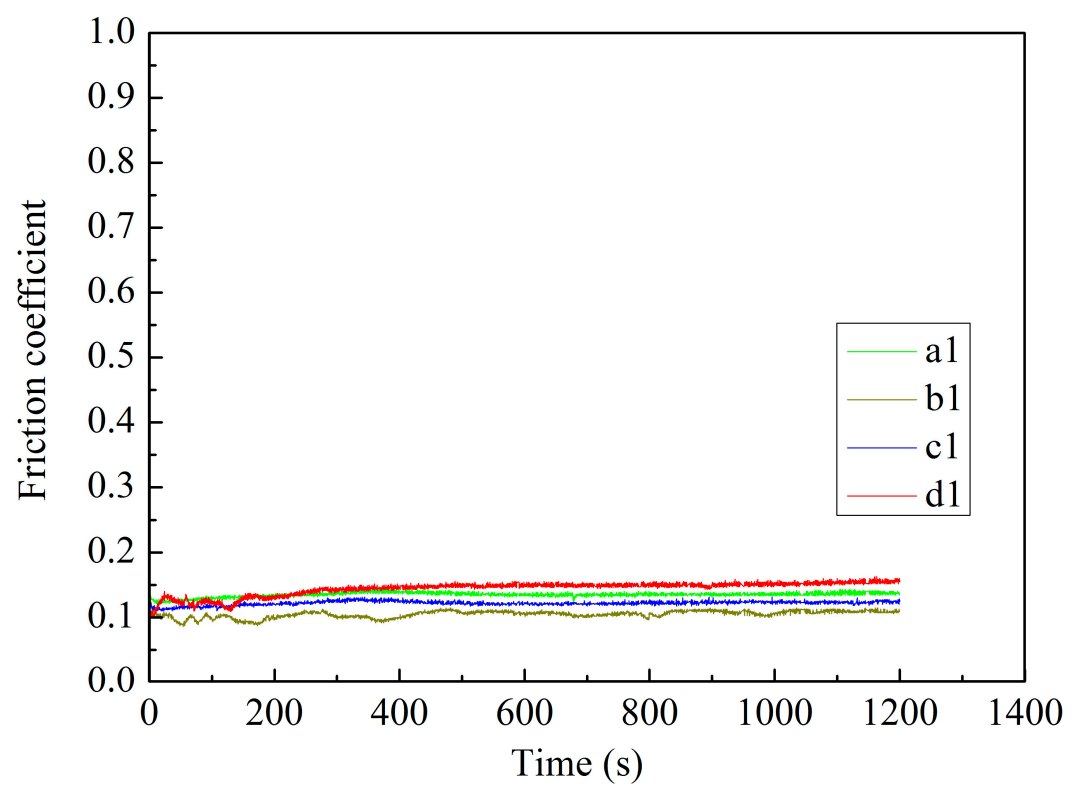

Figure 14. Friction coefficient of microarc oxidation self-lubricating composite coatings formed on aluminum alloy at different cathode current densities. (a1) $9 \mathrm{~A} / \mathrm{dm}^{2}$; (b1) $18 \mathrm{~A} / \mathrm{dm}^{2}$; (c1) $27 \mathrm{~A} / \mathrm{dm}^{2}$; (d1) $37 \mathrm{~A} / \mathrm{dm}^{2}$.
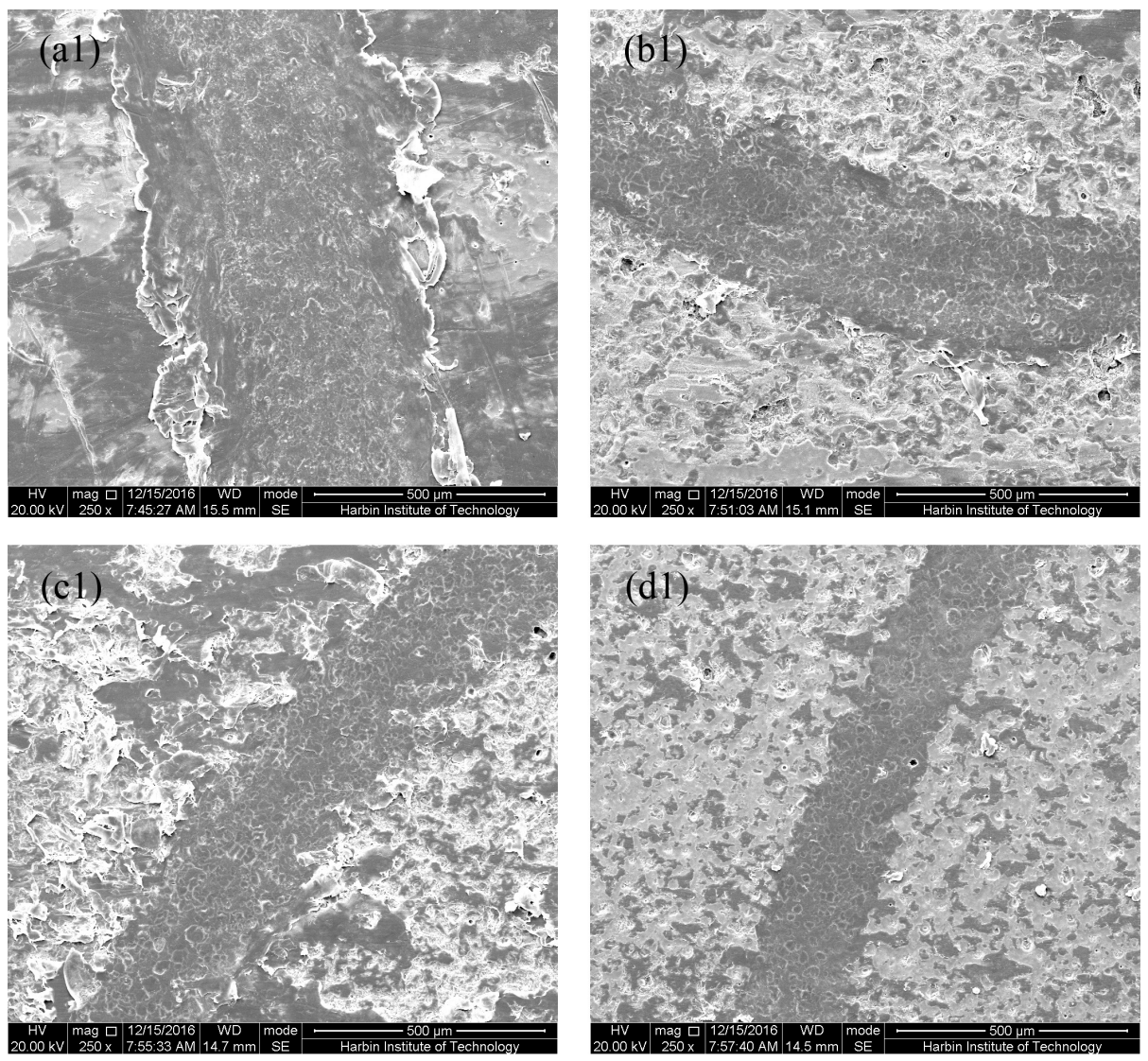

Figure 15. The morphologies of wear tracks for MAO self-lubricating composite coatings formed on aluminum alloy at different cathode current densities. (a1) $9 \mathrm{~A} / \mathrm{dm}^{2}$; (b1) $18 \mathrm{~A} / \mathrm{dm}^{2}$; (c1) $27 \mathrm{~A} / \mathrm{dm}^{2}$; (d1) $37 \mathrm{~A} / \mathrm{dm}^{2}$. 


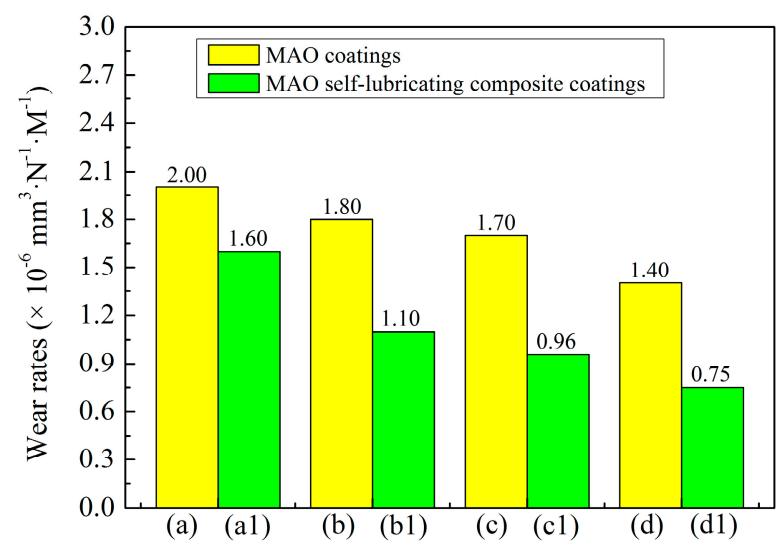

Figure 16. The wear rates of MAO coatings and MAO self-lubricating composite coatings formed on aluminum alloy at different cathode current densities. (a/a1) $9 \mathrm{~A} / \mathrm{dm}^{2}$; (b/b1) $18 \mathrm{~A} / \mathrm{dm}^{2}$; (c/c1) $27 \mathrm{~A} / \mathrm{dm}^{2} ;(\mathbf{d} / \mathrm{d} 1) 37 \mathrm{~A} / \mathrm{dm}^{2}$.

\section{Conclusions}

2024-T4 aluminum alloy was treated by microarc oxidation in the silicate system electrolyte using pulsed bipolar power supply at different cathode current densities. The microarc oxidation self-lubricating composite coatings were prepared by depositing the PTFE in the micropores and microcracks on the surface of MAO ceramic coatings.

The compactness and hardness of the MAO coatings and the bonding strength between MAO coatings and substrates increased as the cathode current density increased. The surface roughness and the thickness of MAO coatings increased as the cathode current density increased. The wear rates of MAO ceramic coatings decreased significantly with the increase in cathode current density.

The microarc oxidation self-lubricating composite coatings, which integrated the advantages of MAO coatings' wear resistance and a low friction coefficient of PTFE, possessed superior tribological properties. Compared to MAO coatings, MAO self-lubricating composite coatings exhibited lower friction coefficient and lower wear rates.

Acknowledgments: The authors gratefully acknowledge the Micro/Nano Technology Research Center, Harbin Institute of Technology for device support.

Author Contributions: Zhenwei Li conceived, designed, and performed the experiments. Zhenwei Li analyzed the data and wrote the manuscript. Shichun Di reviewed the manuscript.

Conflicts of Interest: The authors declare no conflict of interest.

\section{References}

1. Wang, X.S.; Guo, X.W.; Li, X.D.; Ge, D.Y. Improvement on the fatigue performance of 2024-T4 alloy by synergistic coating technology. Materials 2014, 7, 3533-3546. [CrossRef]

2. Wang, P.; Li, J.P.; Guo, Y.C.; Yang, Z.; Wang, J.L. Ceramic coating formation on high Si containing Al alloy by PEO process. Surf. Eng. 2016, 32, 428-434. [CrossRef]

3. Rao, R.N.; Das, S.; Mondal, D.P.; Dixit, G. Effect of heat treatment on the sliding wear behavior of aluminium alloy (Al-Zn-Mg) hard particle composite. Tribol. Int. 2010, 43, 330-339. [CrossRef]

4. Tseng, C.C.; Lee, J.L.; Kuo, T.H.; Kuo, S.N.; Tseng, K.H. The influence of sodium tungstate concentration and anodizing conditions on microarc oxidation (MAO) coatings for aluminum alloy. Surf. Coat. Technol. 2012, 206, 3437-3443. [CrossRef]

5. Polat, A.; Makaraci, M.; Usta, M. Influence of sodium silicate concentration on structural and tribological properties of microarc oxidation coatings on 2017A aluminum alloy substrate. J. Alloys Compd. 2010, 504, 519-526. [CrossRef]

6. Nimura, K.; Sugawara, T.; Jibiki, T.; Ito, S.; Shima, M. Surface modification of aluminum alloy to improve fretting wear properties. Tribol. Int. 2016, 93, 702-708. [CrossRef] 
7. Wang, Z.J.; Wu, L.; Qi, Y.L.; Cai, W.; Jiang, Z.H. Self-lubricating $\mathrm{Al}_{2} \mathrm{O}_{3} /$ PTFE composite coating formation on surface of aluminium alloy. Surf. Coat. Technol. 2010, 204, 3315-3318. [CrossRef]

8. Tsutumi, Y.; Niinomi, M.; Nakai, M.; Shimabukuro, M.; Ashida, M.; Chen, P.; Doi, H.; Hanawa, T. Electrochemical surface treatment of a $\beta$-titanium alloy to realize an antibacterial property and bioactivity. Metals 2016, 6, 76. [CrossRef]

9. Yavari, S.A.; Necula, B.S.; Fratila-Apachitei, L.E.; Duszczyk, J.; Apachitei, I. Biofunctional surfaces by plasma electrolytic oxidation on titanium biomedical alloys. Surf. Eng. 2016, 32, 411-417. [CrossRef]

10. Han, O.S.; Hwang, M.J.; Song, Y.H.; Song, H.J.; Park, Y.J. Effects of surface structure and chemical composition of binary Ti alloys on cell differentiation. Metals 2016, 6, 150. [CrossRef]

11. Mioc, U.B.; Stojadinovic, S.; Nedic, Z. Characterization of bronze surface layer formed by microarc oxidation process in 12-tungstophosphoric acid. Materials 2010, 3, 110-126. [CrossRef]

12. Cheng, Y.L.; Xue, Z.G.; Wang, Q.; Wu, X.Q.; Matykina, E.; Skeldon, P.; Thompson, G.E. New findings on properties of plasma electrolytic oxidation coatings from study of an Al-Cu-Li alloy. Electrochim. Acta 2013, 107, 358-378. [CrossRef]

13. Chen, M.A.; Ou, Y.C.; Yu, C.Y.; Xiao, C.; Liu, S.Y. Corrosion performance of epoxy/BTESPT/MAO coating on AZ31 alloy. Surf. Eng. 2016, 32, 38-46. [CrossRef]

14. Guan, Y.J.; Xia, Y.; Xu, F.T. Interface fracture property of PEO ceramic coatings on aluminum alloy. Surf. Coat. Technol. 2008, 202, 4204-4209. [CrossRef]

15. Martin, J.; Leone, P.; Nomine, A.; Renaux, D.V.; Henrion, G.; Belmonte, T. Influence of electrolyte ageing on the plasma electrolytic oxidation of aluminium. Surf. Coat. Technol. 2015, 269, 36-46. [CrossRef]

16. Hussein, R.O.; Northwood, D.O.; Su, J.F.; Xie, X. A study of the interactive effects of hybrid current modes on the tribological properties of a PEO (plasma electrolytic oxidation) coated AM60B Mg-alloy. Surf. Coat. Technol. 2013, 215, 421-430. [CrossRef]

17. Wu, H.H.; Lu, X.Y.; Long, B.H.; Wang, X.Q.; Wang, J.B.; Jin, Z.S. The effects of cathodic and anodic voltages on the characteristics of porous nanocrystalline titania coatings fabricated by microarc oxidation. Mater. Lett. 2005, 59, 370-375. [CrossRef]

18. Liu, F.; Xu, J.L.; Yu, D.Z.; Wang, F.P.; Zhao, L.C. Effects of cathodic voltages on the structure and properties of ceramic coatings formed on NiTi alloy by microarc oxidation. Mater. Chem. Phys. 2010, 121, 172-177. [CrossRef]

19. Su, P.B.; Wu, X.H.; Guo, Y.; Jiang, Z.H. Effects of cathode current density on structure and corrosion resistance of plasma electrolytic oxidation coatings formed on ZK60 Mg alloy. J. Alloys Compd. 2009, 475, 773-777. [CrossRef]

20. Li, Q.B.; Liang, J.; Liu, B.X.; Peng, Z.J.; Wang, Q. Effects of cathodic voltages on structure and wear resistance of plasma electrolytic oxidation coatings formed on aluminium alloy. Appl. Surf. Sci. 2014, 297, 176-181. [CrossRef]

21. Mu, M.; Zhou, X.J.; Xiao, Q.; Liang, J.; Huo, X.D. Preparation and tribological properties of self-lubricating $\mathrm{TiO}_{2}$ /graphite composite coating on TI6Al4V alloy. Appl. Surf. Sci. 2012, 258, 8570-8576. [CrossRef]

22. Wang, S.Y.; Si, N.C.; Xia, Y.P.; Liu, L. Influence of nano-SiC on microstructure and property of MAO coating formed on AZ91D magnesium alloy. Trans. Nonferrous Met. Soc. China 2015, 25, 1926-1934. [CrossRef]

23. Hussein, R.O.; Xie, X.; Northwood, D.O.; Yerokhin, A.; Matthews, A. Spectroscopic study of electrolytic plasma and discharging behavior during the plasma electrolytic oxidation (PEO) process. J. Phys. D Appl. Phys. 2010, 43, 105203-105215. [CrossRef]

24. Tekin, K.C.; Malayoglu, U.; Shrestha, S. Tribological behaviour of plasma electrolytic oxide coatings on Ti6Al4V and cp-Ti alloys. Surf. Eng. 2016, 32, 435-442. [CrossRef]

(C) 2017 by the authors. Licensee MDPI, Basel, Switzerland. This article is an open access article distributed under the terms and conditions of the Creative Commons Attribution (CC BY) license (http:/ / creativecommons.org/licenses/by/4.0/). 